\title{
Nuclear Theory Centre Targets Interfaces
}

A European Theoretical Centre for studies in nuclear physics and related areas (ECT* $^{*}$ for short) was just a dream a year ago. Today it's a reality: programmes are being held and the secretariat is housed in new premises adjacent to the villa on the outskirts of Trento in northern Italy that will one day become part of the ECT*'s permanent home. An offical inaguration was clearly appropriate and this was held on 10-11 September in Trento at the Istituto Trentino di Cultura (ITC), the ECT"s umbrella organization (the form of the relationship may change as the ECT develops). Without dwelling on how Trento came to be selected as the site for a European nuclear theory centre [EN 23 (1992) 180], one should acknowledge the support from the Trento-Alto Adige regional government through ITC (a 1000 MLIT annual grant for five years, plus services)

The region, with a population of 0.8 million and autonomous since World War II, practices an active policy in science, with the ITC as a special instrument. Among the ITC's affiliates are research centres for mathematics and for science - the latter employing 150 people. Meanwhile, the University of Trento (11000 students; 5 nuclear theorists in the physics department) enjoys financial advantages under a 1982 law reflecting the region's autonomy.

The ICT Director speaking at the opening ceremony described the ECT*'s challenges as applying to the whole of science, where effective research is international, contacts between theory and experiment must be reinforced, and development of the community must come from the base. The centre aims to stress the training of young theorists via focussed programmes and by hosting visitors, especially postdocs, for extended stays.

G.P. Picozza, the Vice-President of the Istituto Nazionale di Fisica Nucleare (INFN), indicated that the INFN recognizes the importance of a nuclear theory centre as a European focus, and will provide support "in the spirit of independence". It will be up to the INFN committee responsible for nuclear physics to recommend whether successful and stable operation justifies regular support in the form of say fellowships. The INFN will meanwhile cover the expenses of INFN staff visiting the centre for workshops of 1-2 weeks duration (seven in 1994) and a summer institute aimed at students.

It is natural to compare the ECT* with the Institute for Nuclear Theory (INT) set up at the University of Washington, Seattle, WA, USA, four years ago as they share similar objectives. The INT has a small permanent staff with a Director (W. Haxton, who took over last year from E. Henley, the interim Director) and two senior fellows. The programmes (usually 3 each year lasting 2-3 months with a graduate school linked to the summer programme) basically imply living expenses for participants, and only exceptionally salaries. They are covered by a 5-year 1.3 M\$US Department of Energy grant; local support comprises mostly facili- ties in Washington University's new physics building. The main criticisms which the INT has met with from its Council are that programmes (which are proposed to the DoE by a national advisory committee) are too diffuse, while too many $(\approx 65 \%)$ of the participants (mostly senior scientists with $30 \%$ postdocs and few graduate students) do not attend an entire programme.

G. Bertsch, an INT senior fellow, remarked that there was room for the two centres to complement each other, especially if the $\mathrm{ECT}^{\star}$ succeeds in attracting younger visitors. Nonetheless, coordination is important and cross-Atlantic "spillovers" are envisaged. $\mathrm{He}$ felt that the true test of the value of the ECT* will come when the level of European Community support is negotiated. Brussels, of course, does not operate like the DoE and is unwilling to provide long-term, basic funding but aims to promote multi-partner initiatives within existing programmes emphasizing needs in less-developed regions. The main option is support under the Human Capital and Mobility (HCM) Programme, and indeed the $\mathrm{ECT}^{*}$ was selected in the last $\mathrm{HCM}$ round for institutional fellowships (page 186).

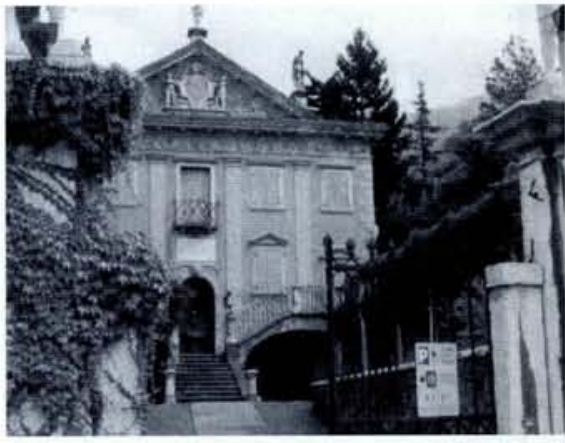

Villa Tambosi in Villazzano on the outskirts of Trento which, once renovated, will form the main part of the $E C T^{\star}$ complex.

R. Leonardi, Dean of the science faculty and scientific secretary and a prime mover in creating the ECT*, points out that the centre may need to experiment to optimize activities and topic selection. The inaugural symposium stressed the importance of interfaces with other fields, without forgetting the mainstreams of nuclear physics such as heavyion reactions where facilities are generating a wealth of new data ( $P$. Kienle), and nuclear structure theory where many systematic effects need assimilation (G. Bertsch).

The ECT* has a Board of Directors, endorsed by NuPECC, which meets three times each year to decide programmes. D. Brink, a nuclear theoretican from Oxford University, became the Vice-Director in July when B. Mottelson from NORDITA stood down as Chairman of the Board to become the Director, working half-time in Trento.

Information on the ECT* programmes from: $\mathrm{ECT}^{*}$ Secretariat (L. Attardi), Dip. di Fisica, Università degli Studi di Trento, I-38050 Povo (Tel.: +39-461 881508 ; fax: $+39-461-881699$; email: preside@itncisca.bitnet).

\section{Societies Endorse Greater Engagement}

The sound development of European-level activities, covering a wider spectrum, needs the engagement with EPS to be strengthened and balanced in a more realistic way between large and small national societies, and between the different types of members within a society. The Presidents of national societies, meeting with the Executive Committee in Florence just before the EPS-9 General Conference last month, endorsed proposals on ways this can be done by opening up Divisional and other EPS activities to national society members, and by keeping them informed via Europhysics News distributed in bulk through their societies.

A careful analysis of the financial implications is clearly needed before preparing a proposal for Council in Cracow next March. It had therefore been agreed at the last Council (in March in Nice) that the societies would be asked before the meeting with the Presidents if they wished to pay a proportional unit fee and receive Europhysics News mailed in bulk to a declared number of full members. A total of 19 said yes and one society replied that for financial reasons it was unable to decide.

Instead of today's sliding scale for the fee structure whereby large societies pay somewhat less per member than small ones, under the new arrangement all participate on an equal footing: they contribute for each member on a proportional basis determined by the fee an individual pays to his or her society. The contribution to EPS may, for instance, be less for a student than for a full member (e.g., a research physicist working in industry or academia) if a national society levies different fees: it is up to each society to tell EPS how many members it has in each membership category. The only exceptional feature is that the two largest societies (The UK's Institute of Physics and the German Physical Society - the DPG) publish EPS and Division material in their national bulletins instead of distributing Europhysics News. 